\title{
Los programas formativos como medida penal alternativa en los casos de violencia de género ocasional'.
}

\author{
Elena Larrauri \\ Universidad Pompeu Fabra
}

Manuscrito recibido el 5 de enero de 2010 / Publicado el 19 de febrero de 2010

\section{RESUMEN}

En este estudio se estudia el proceso de ejecución de los Programas Formativos o de tratamiento que se imponen a las personas condenadas por violencia de género como medida penal alternativa a la pena de prisión. Se sigue el itinerario cronológico de ejecución en Catalunya y se destaca la problemática con la que se enfrentan los jueces encargados de la ejecución de esta medida; los delegados de ejecución, quienes hacen de puente entre la persona condenada, el sistema judicial y las instituciones donde se realizan los programas formativos; y finalmente se expone la perspectiva de las instituciones y psicólogos que realizan las sesiones. El estudio finaliza con una serie de reflexiones dirigidas a conseguir que esta medida penal alternativa sea una pena directa principal y se aplique no sólo a personas condenadas de bajo riesgo.

Palabras clave: Violencia de género. Suspensión de pena. Penas comunitarias. Programas de tratamiento

\section{ABSTRACT}

This paper deals with 'treatment orders' or 'educational programs' as a community penalty applied to people sentenced of gender violence. The paper follows the implementation of this penalty and tries to focus on the problems that confront the different actors that intervene in it. In the first part the judicial system is analyzed, in the second place we show the problems that face the probation officers in Catalunya, and finally we approach the perspective of the psychologists who engage directly in the work with the sentenced men for gender violence.

Keywords: Gender Violence. Suspended Sentence. Community Sentences. Treatment Programs.

\footnotetext{
${ }^{1}$ Este trabajo se inscribe en el Proyecto de Investigación Género y Marginación. (DER 2009-08344/JURI). Se ha beneficiado también de dos ayudas del CEJFE (Departament de Justicia: JUS/3967/2007 y JUS/4122/2008). Son muchas las personas que han contribuido con sus comentarios a la redacción final. En especial quisiera dejar constancia de mi agradecimiento a Marc Cerón, Subdirector General de Reparació i Execució Penal a la Comunitat del Departament de Justícia de Catalunya; Manuela Moreno, técnica encargada de los Programas Formativos; Lidia Serratusell, Cap de la Unitat de Programes de la Subdirecció General de Reparació i Execució Penal a la Comunitat del Departament de Justícia; Juanjo Subero, jefe de la Unidad de Medidas Penales Alternativas. Muchas gracias también a los magistrados Josep Antoni Rodríguez y Maria Dolors Leyva, jueces de ejecución de Barcelona, por ayudarme en la comprensión de diversos aspectos relacionados con la ejecución de esta medida. Quisiera apresurarme en advertir que cualquier error es atribuible a mi interpretación y posterior redacción de la información recibida.

Heinrich Geldschläger (IRES) y Dave Morran (Dept. Applied Social Science, University of Stirling) me han aportado sus conocimientos y experiencia práctica. Por discusiones siempre fructíferas gracias a los profesores Ester Blay, Josep Cid, Gonzalo Escobar y Daniel Varona. El profesor William Freddy Pérez, como siempre, ha mejorado la redacción del texto.
}

Revista Española de Investigación Criminológica

Artículo 1, Número 8 (2010) $\quad$ www.criminología.net

ISSN: $1696-9219$ 


\section{INTRODUCCION}

La posibilidad de imponer la obligación de realizar un programa formativo fue introducida en el Código Penal de 1995, como una regla de conducta en los casos en que el juez suspendiese la pena de prisión; de este modo el sistema español de suspensión de la pena se aproximaba al sistema de la probation anglosajona (CID/LARRAURI, 2005; CID, 2009)

Los programas formativos pueden imponerse como regla de conducta en todos los casos de suspensión de la pena de prisión (inferior a dos años y siempre que la persona carezca de antecedentes) o sustitución ${ }^{2}$, aunque son usados mayormente en el ámbito de la delincuencia vinculada con la seguridad vial, en los delitos de violencia doméstica y de violencia de género.

Si bien la ejecución de esta medida previsiblemente sigue un itinerario similar en estos tres delitos y plantea problemáticas similares, una diferencia es que mientras que en los dos primeros casos el juez puede imponer la obligación de asistir a un programa formativo, en el caso de la violencia de género esta regla de conducta es obligada.

En efecto, la Ley Integral (LO 1/2004 de 28 de diciembre de Medidas de Protección Integral contra la Violencia de Género), cuya regulación penal entró en vigor el 29 de Junio de 2005, obligó a que en todos los casos de suspensión (o sustitución) de la pena de prisión impuesta por la comisión de un delito de violencia de género se añadiera la obligación de acudir a un Programa Formativo (art.83.1 in fine y artículo 88.1 in fine del código penal).

Es necesario advertir que si bien la obligación de asistir a un Programa Formativo debe imponerse en todos los casos de delitos de violencia de género en que se suspenda o sustituya la pena de prisión, en la práctica la mayoría de personas que asisten a estos programas suelen ser agresores condenados por violencia ocasional (art. $153 \mathrm{CP}$ ), esto es, de bajo riesgo.

El Código Penal se refiere a estos programas, unas veces como 'programas formativos' (art.83.1,5a), otras como 'programas de reeducación' y otras como 'tratamiento psicológico' (art.88.1). Aunque soy consciente de que estas

\footnotetext{
${ }^{2}$ La suspensión de la pena de prisión no es posible si la persona tiene antecedentes penales o la pena es superior a dos años de prisión. La sustitución de la pena de prisión de un año (o de dos años), aunque se impone de forma muy excepcional, es posible respecto de personas con antecedentes penales.
}

Revista Española de Investigación Criminológica

Artículo 1, Número 8 (2010) $\quad$ www.criminología.net

ISSN: $1696-9219$ 
denominaciones tienen diferentes significados, en este estudio usaré estos términos indistintamente.

Los Programas Formativos se basan en unas entrevistas individuales (motivacionales) y en la participación en sesiones de terapia grupales, en las cuales, con diversas técnicas psicológicas de 'role playing', resolución de problemas, se intenta incidir en las habilidades, las actitudes y las creencias culturales de las personas que se presume están relacionadas con la comisión del delito.

Por último también debe recordarse que si bien existen Programas de Tratamiento en prisión ${ }^{3}$ y existen Programas Formativos comunitarios voluntarios, en la exposición que prosigue me concentro en los que son considerados Medidas Penales Alternativas, esto es, los que se cumplen como consecuencia de la suspensión y sustitución de una pena de prisión y son supervisados por la Direcció General de Reparació i Execució Penal a la Comunidad i de Justícia Juvenil de la Generalitat de Catalunya.

Antes de exponer la ejecución de los programas formativos es conveniente recordar la regulación penal de los delitos de violencia de género. Por ello abordaré en primer lugar el delito de violencia de género ocasional y las penas con que se castiga, y posteriormente expondré la aplicación y los problemas que la ejecución de estos programas ocasiona, para finalizar con unas propuestas de reforma.

\section{1.- EL DELITO DE VIOLENCIA DE GÉNERO OCASIONAL}

En España el legislador introdujo el delito de violencia doméstica en 1989. Con él se pretendía superar el hecho de que la poca entidad lesiva del resultado, frecuente en las 'peleas domésticas', llevara a calificar estos sucesos siempre como falta. Por ello se creó un delito especifico de violencia doméstica que puso el acento en castigar con una pena de prisión a quien habitualmente realice maltratos sobre una persona del círculo doméstico (independientemente de que el resultado fuera leve).

Después de numerosas reformas penales una nueva ley (LO 11/2003 de 29 de septiembre 2003) convirtió en delito el maltrato ocasional ${ }^{4}$. Ello conllevó la posibilidad

\footnotetext{
${ }^{3}$ De acuerdo con el Informe Ejecutivo del Ministerio de Igualdad (2008:23) un total de 466 internos han participado en estos cursos entre los años 2005-2008. No se aporta más información y nada se dice de si los programas han sido o serán evaluados. Para una evaluación referida a los programas penitenciarios en Cataluña puede verse MARTÍNEZ/PÉREZ (2009).

${ }^{4}$ Esta reforma penal eleva la falta de lesión (maltrato de obra que sana por el mero transcurso del tiempo o una lesión que requiere una primera asistencia facultativa) a delito de violencia ocasional (del art.153), siempre que se dirijan a un miembro de la unidad familiar. La violencia habitual pasa a ser castigada en el
}

Revista Española de Investigación Criminológica

Artículo 1, Número 8 (2010) $\quad$ www.criminología.net

ISSN: $1696-9219$ 
de imponer una pena de prisión o trabajo en beneficio a la comunidad (TBC) a un comportamiento que antes era catalogado de falta y castigado normalmente con una multa.

Por tanto, desde el año 2003 el comportamiento de violencia ocasional en el ámbito doméstico es un delito y en consecuencia los jueces pueden imponer una pena de prisión. De acuerdo con nuestras investigaciones (ANTÓN/LARRAURI, 2009), es lo que los jueces hicieron en esta primera etapa, desde Septiembre del 2003 hasta Junio del 2005, condenando a pena de prisión en un $82,6 \%$ de las ocasiones y a trabajo en beneficio a la comunidad en el restante 17,4\%. Esta pena de prisión se suspende en un 56,5\% y se sustituye en un $28,7 \%$, por lo que la entrada en prisión se produce en un $14,8 \%$ (véase Gráfico1).

A partir de la Ley Integral, al delito de violencia ocasional del artículo 153 se le añade una agravación de la pena si el maltrato se dirige contra la mujer pareja (o persona especialmente vulnerable) ${ }^{5}$.

En consecuencia, actualmente en España la violencia ocasional cuando recae sobre la mujer pareja es un delito que se denomina violencia de género y tiene una pena mayor que si se dirige contra otro miembro de la unidad familiar ${ }^{6}$. A efectos de facilitar el seguimiento se reproduce el artículo 153.

El que por cualquier medio o procedimiento causare a otro menoscabo psíquico o una lesión no definidos como delito en este Código, o golpeare o maltratare de obra a otro sin causarle lesión, cuando la ofendida sea o haya sido esposa, o mujer que esté o haya estado ligada a él por una análoga relación de afectividad aun sin convivencia, o persona especialmente vulnerable que conviva con el autor, será castigado con la pena de prisión de seis meses a un año o de trabajos en beneficio de la comunidad de treinta y uno a ochenta días....

Después de la entrada en vigor de la Ley Integral, la aplicación de la pena de prisión se ha reducido en comparación con la primera etapa investigada, fundamentalmente por el impacto del trabajo en beneficio a la comunidad que alcanza el $39,2 \%$. No obstante la respuesta judicial más habitual a los delitos de violencia de género ocasional del art.153 sigue siendo la pena de prisión, la cual se impone en un $60,8 \%$ de las ocasiones (Gráfico1).

art.173.2. La unidad familiar además se amplía a hermanos, a cualquier persona integrada en el núcleo de convivencia familiar e incluso a ancianos asistidos en centros públicos.

${ }^{5}$ Esta agravación se produce también en los delitos de amenazas, coacciones y lesiones.

${ }^{6}$ Un resumen de la discusión que esta diferente penalidad ha ocasionado se encuentra expuesta en

LARRAURI (2009a; 2009b)

Revista Española de Investigación Criminológica

Artículo 1, Número 8 (2010) $\quad$ www.criminología.net

ISSN: $1696-9219$ 


\section{Gráfico 1: Penas impuestas}

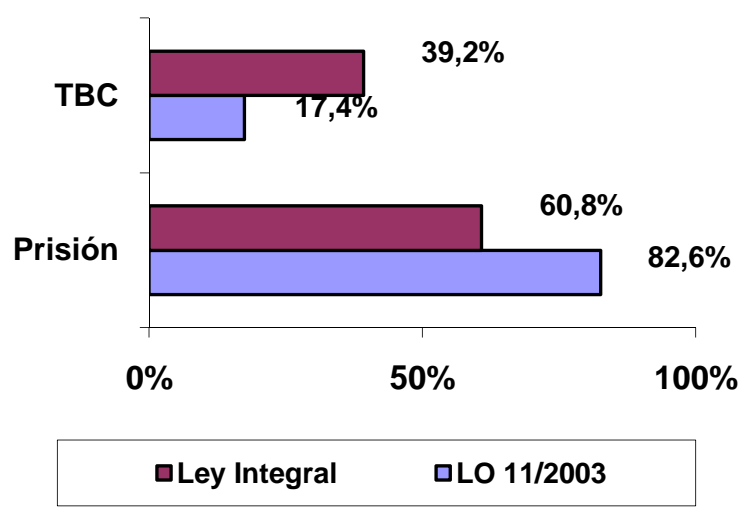

Ahora bien, hay que insistir en el hecho de que en España el juez puede suspender la pena de prisión(con la obligación de no delinquir durante un periodo fijado por la ley), siempre y cuando las penas correspondientes sean inferiores a dos años de prisión y la persona haya delinquido por primera vez. Ese es el proceder más habitual de los jueces $^{7}$. Así, de acuerdo con los resultados de nuestra investigación respecto de la violencia de género ocasional (del artículo 153), los jueces suspenden la pena de prisión en un 70,7\% de las ocasiones (Gráfico 2) (ANTÓN/LARRAURI 2009).

Gráfico 2: Porcentaje de suspensiones, sustituciones y ejecuciones de penas privativas de libertad respecto del total de condenados a prisión

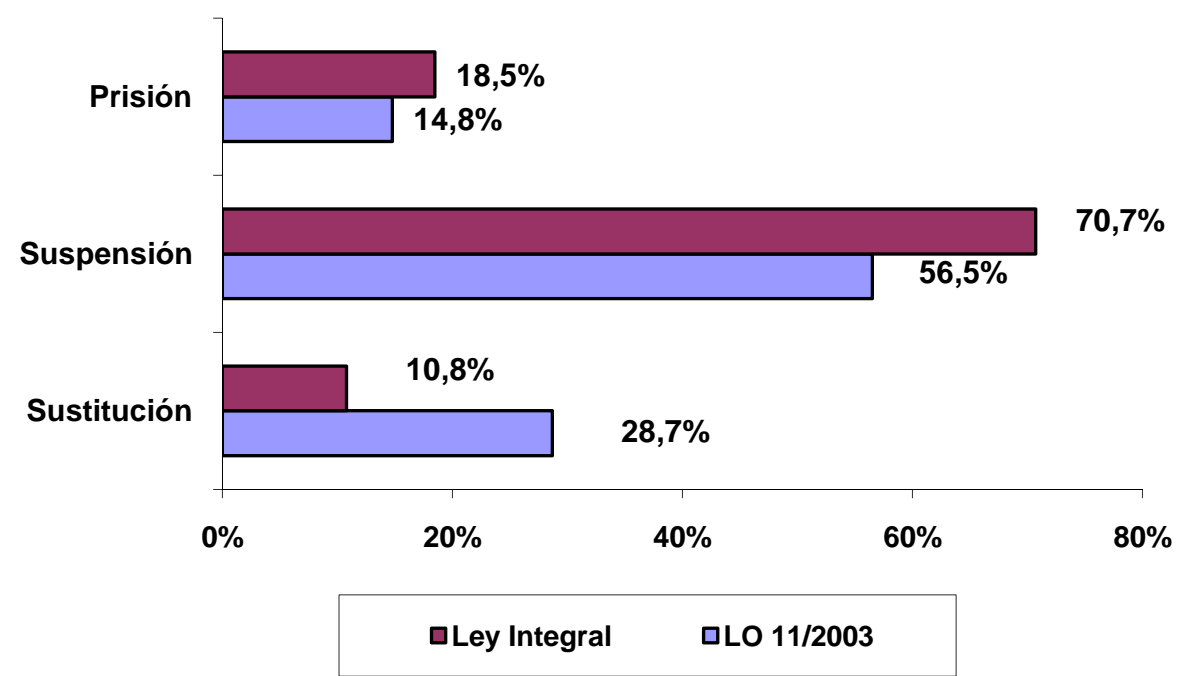

\footnotetext{
${ }^{7}$ De acuerdo a otras investigaciones que se han llevado a cabo (CID/LARRAURI, 2002:58), si no hay antecedentes penales y la pena de prisión es menor a dos años, los jueces suspenden la pena en el $84 \%$ de los casos.
}

Revista Española de Investigación Criminológica

Artículo 1, Número 8 (2010) $\quad$ www.criminología.net

ISSN: $1696-9219$ 


\section{LOS PROGRAMAS FORMATIVOS O DE TRATAMIENTO: LA EXPERIENCIA DE CATALUÑA}

El legislador de la ley integral, como ya he expuesto, decidió añadir más reglas de conducta a la suspensión de la pena de prisión en los casos de delitos de violencia de género. Además de la obligación de no delinquir durante el periodo de suspensión, y de la prohibición de aproximarse a la víctima ${ }^{8}$, desde la entrada en vigor de la Ley Integral el juez ha de imponer de forma obligatoria al condenado la obligación de asistir a un Programa Formativo, cuando suspende la pena de prisión?

Es curioso que el legislador español optara por introducir estos programas formativos, especialmente considerando la tradicional falta de apoyo a los mismos tanto desde sectores feministas como desde la propia doctrina penalista (LARRAURI, 2004) $)^{10}$.

Las críticas respecto del tratamiento en España eran semejantes al escepticismo que la rehabilitación suscitaba en Estados Unidos y en Europa. Pero el hecho de que España viviera bajo una dictadura durante los años sesenta y setenta hizo que el objetivo rehabilitador, que se identificaba principalmente con programas psicológicos dirigidos a cambiar valores, se considerase especialmente sospechoso. La imagen de los presos políticos como opositores políticos respecto de los cuales era ilegítimo cualquier cambio de valores, fue extendida a todos los demás delitos. Como consecuencia, los programas psicológicos se han visto con desconfianza por autores influyentes de la doctrina penalista contemporánea, como por ejemplo MUÑOZ CONDE (1979), en cuyo artículo puede leerse una visión crítica característica de la época respecto de los programas de tratamiento (pero léase también una respuesta en BUENO ARÚS, 1985).

Además de la posición general contraria al tratamiento en la penología española, hay grupos feministas también en contra de la aplicación de estos programas a los condenados por violencia de género. Principalmente porque se consideran inefectivos y

\footnotetext{
${ }^{8}$ La prohibición de comunicarse y aproximarse a la víctima son obligatorias desde la LO 15/2003.

${ }^{9}$ Un análisis jurídico de la regulación puede leerse en RUEDA (2007)

${ }^{10}$ Uno de los motivos que quizás explica la opción adoptada por el legislador de generalizar la imposición de los programas de tratamiento es la experiencia que sobre ellos existía en los centros penitenciarios. Véase ECHEBURÚA, E. / FERNÁNDEZ-MONTALVO, J. (2007); FERNÁNDEZMONTALVO, J. / ECHEBURÚA, E. / AMOR, P. (2005); y REDONDO, S. / POZUELO, F. / RUIZ, A. (2007). Agradezco esta idea a José Cid.
}

Revista Española de Investigación Criminológica

Artículo 1, Número 8 (2010) $\quad$ www.criminología.net

ISSN: $1696-9219$ 
porque envían el erróneo mensaje de que los condenados son hombres enfermos; porque evita que ellos sean castigados con penas severas; y finalmente, porque en aquellos programas se usan recursos que podrían ser destinados a servicios para las mujeres.

A pesar de esta falta de apoyo, la obligación de imponer programas formativos a los hombres condenados por violencia de género ha sido introducida por la Ley Integral en España en el año 2005, probablemente debido a varias razones.

Primero, el clima penal cada vez más punitivo lleva a la idea según la cual, si la pena se suspende, 'algo' tiene que imponerse al condenado (BOTTOMS/REX/ROBINSON, 2004). Segundo, la posible influencia en España de lo que se ha denominado la 'nueva ortodoxia' de los programas basados en el método cognitivo-conductual (ROBINSON/MCNEILL, 2004), provenientes del mundo anglosajón y Canadá. Y una tercera razón para introducir los programas formativos es posiblemente la 'falta de alternativas' visibles, especialmente debido a las críticas que ha recibido la pena de multa, que fue abolida como pena directa para casos de violencia de género en la reforma de 2003 y como pena sustitutiva de la prisión un año después, con la aprobación de la Ley Integral.

Por lo que respecta a la aplicación de los Programas Formativos en Cataluña, los jueces añaden la obligación de participar en un Programa Formativo en un 76,6\% de los casos en los que suspenden la pena de prisión (ANTÓN/LARRAURI, 2009, Gráfico 3).

Puede causar una cierta sorpresa que la cifra no sea de un $100 \%$ puesto que, como he explicado, el juez debe imponerlos obligatoriamente. Quizás este dato sería distinto en la actualidad, producto de un mayor conocimiento de la Ley Integral o de una mayor confianza en los programas formativos. Pero no sabemos exactamente las razones de por qué no se aplican siempre y para averiguarlo se necesitaría otro tipo de investigación ${ }^{11}$.

\footnotetext{
${ }^{11}$ Los motivos por los cuales algunos jueces de ejecución no imponen siempre Programas Formativos cuando suspenden la pena de prisión pueden ser : a) Todos los jueces no sabían aun, en el momento en que se realizó la investigación, que la Ley Integral les obligaba a imponer siempre un Programa Formativo; b) Hay jueces que opinan que a pesar de lo que indica el código penal, la 'parte' debe pedir que se imponga el programa formativo; c) Hay jueces que creen que no hay plazas en los programas formativos; d) Hay jueces que creen que no siempre son necesarios, pues la persona está 'normalizada'; e) Hay jueces que no los imponen porque advierten problemas de idioma o de alcoholismo y presumen que quizás estos no pueden ser tratados en el marco de un programa formativo. En definitiva, no sabemos porque no los imponen.
}

Revista Española de Investigación Criminológica

Artículo 1, Número 8 (2010) $\quad$ www.criminología.net

ISSN: $1696-9219$ 


\section{Gráfico 3: Aplicación de la obligación de realizar programas formativos o de tratamiento en casos de suspensión de la pena}

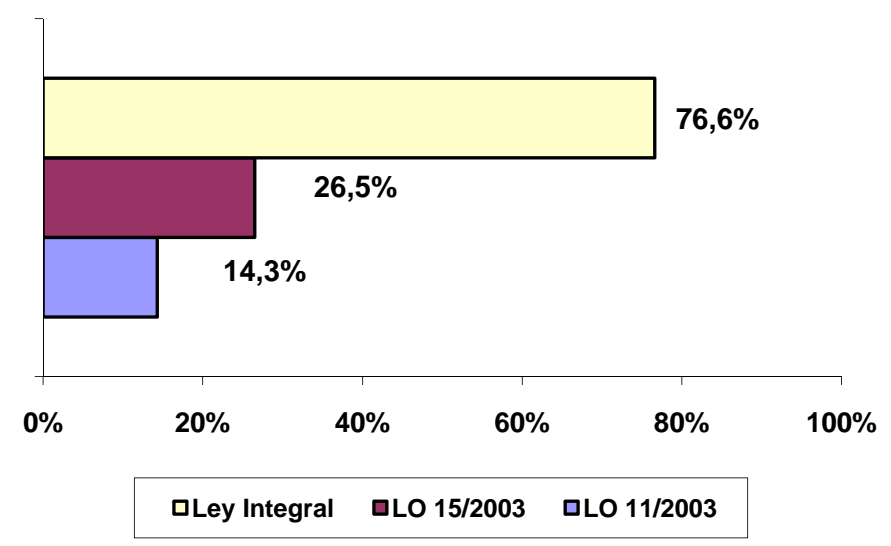

En el conjunto de penas ejecutadas, el número de personas a las que se les ha impuesto un Programa Formativo representa el 30,4\% y es, después del Trabajo en Beneficio a la Comunidad (46,1\%), la pena más ejecutada. En números absolutos, de una muestra de 280 casos, 85 personas deben realizar un programa formativo.

Si la ejecución se contempla desde la perspectiva del volumen de trabajo estos son los datos facilitados por el Departamento de Justicia de Cataluña. En la tabla 1 puede verse el gran aumento en número absolutos de esta pena, especialmente del año 2005 al 2006, cuando devino obligatoria.

Tabla 1: Evolución de los programas formativos en Cataluña

\begin{tabular}{|l|l|l|l|l|l|}
\hline Programas formativos de violencia doméstica y de género & $\mathbf{2 0 0 4}$ & $\mathbf{2 0 0 5}$ & $\mathbf{2 0 0 6}$ & $\mathbf{2 0 0 7}$ & $\mathbf{2 0 0 8}$ \\
\hline Condenados a Programa Formativo & 38 & 294 & 751 & 969 & 985 \\
\hline Hombres & 37 & 287 & 722 & 935 & 855 \\
\hline Mujeres & 1 & 7 & 29 & 34 & 38 \\
\hline Enviados a Programa Formativo & & & & & \\
\hline Grupos & 8 & 40 & 287 & 420 & 682 \\
\hline
\end{tabular}

Fuente: Datos proporcionados por Juanjo Subero, Jefe de la Unidad de Medidas Penales Alternativas.

\footnotetext{
${ }^{12}$ La diferencia entre las personas condenadas y la categoría de 'enviados', hace referencia a la existencia de listas de espera para poder cumplir esta condena.
}

Revista Española de Investigación Criminológica

Artículo 1, Número 8 (2010) $\quad$ www.criminología.net

ISSN: $1696-9219$ 
Voy a destacar a continuación algunos de los problemas que plantea la ejecución de los Programas Formativos, cuyo itinerario se expone al final de este escrito.

\subsection{El proceso de ejecución de la sentencia}

Una vez se ha acordado suspender la pena de prisión, nos encontramos en ocasiones que el Juez de ejecución impone el Programa Formativo de forma automática porque es legalmente obligatorio. En otras, no obstante, acostumbra a pedir un informe psico-social sobre el agresor a los funcionarios del Departamento de Justicia (Equipo de Asesoramiento Técnico, EAT).

La posibilidad de pedir un informe al Equipo de Asesoramiento Técnico en la justicia penal de adultos está prevista en el art.28 del RD 515/2005 de 6 de mayo, por el que se establecen las circunstancias de ejecución de las penas de Trabajos en Beneficio de la Comunidad y de Localización Permanente, de determinadas Medidas de Seguridad, así como de la Suspensión de la ejecución de las penas privativas de libertad.

28. Informes requeridos por autoridades judiciales y por el Ministerio Fiscal. Antes del juicio oral, el juez o tribunal podrá solicitar a los servicios sociales penitenciarios, como prueba documental o pericial, un informe social sobre la situación del imputado.

Estos mismos informes podrán ser solicitados por el Ministerio Fiscal en el curso de sus diligencias o investigaciones.

Asimismo, una vez recaída sentencia, la autoridad judicial podrá solicitar los informes a los que se refieren los apartados anteriores, a los efectos de revisión de medidas, concesión de suspensión de condena, sustitución de penas o adopción de cualquier otra resolución judicial que se entienda requiere tener conocimiento de la situación social del penado o sometido a medida de seguridad.

El escrito que se redacta, realizado con base en alguna entrevista con la persona condenada, muestra las actitudes del agresor en lo que respecta al delito, la relación con la víctima, si tiene problemas con las drogas, y se realiza a partir de un cuestionario de valoración del riesgo, el Spousal Assault Risk Assessment (SARA), una evaluación del riesgo.

La función de este informe es precisamente asistir a los jueces en la toma de decisiones judiciales. Y si bien no es vinculante, ayuda a comprobar si la persona está en condiciones de asistir y no presenta, por ejemplo, problemas de drogadicción o enfermedad que le imposibilitan cumplir el Programa Formativo.

Revista Española de Investigación Criminológica

Artículo 1, Número 8 (2010) $\quad$ www.criminología.net

ISSN: $1696-9219$ 
Cada vez más jueces solicitan este informe psico-social; así, en diciembre del año 2008 se pidieron en Catalunya 391 informes $^{13}$ y si bien no todos son por delitos de Violencia de Género puede estimarse que aproximadamente un $40 \%$ se refieren a este delito. Esta cifra puede parecer pequeña, pero debe considerarse que en enero de ese mismo año se habían solicitado 16 , lo cual revela un rápido crecimiento e indicaría quizás una tendencia creciente de los jueces a solicitar el informe psico-social.

A diferencia de lo que sucede en la justicia penal de menores, en la que existe la obligación de pedir este informe (art.27 de la LO 5/2000 de 12 de enero reguladora de la responsabilidad penal de los menores), en la justicia penal de adultos la petición es opcional, y el hecho de que no todos los jueces lo hagan comportará, como luego veremos, diversos problemas en la ejecución de la medida.

En las entrevistas realizadas con los jueces se percibe un gran desconocimiento de este informe así como de quien debe pedirlo. A mi juicio este informe puede ser solicitado, además del Ministerio Fiscal, por los Jueces de Instrucción (o Jueces Especializados de Violencia sobre la Mujer), por el Juez Penal o por el Juez de Ejecución. Sin embargo, muchos jueces entrevistados desconocen la posibilidad que tienen y siempre creen que lo debe pedir 'otro' (LARRAURI, 2010).

Esta actitud puede obedecer a que los jueces desconocen realmente cuál es la función de este informe e interpretan su solicitud 'en clave de inimputabilidad' (José Antonio Rodríguez, comunicación personal), esto es, interpretan que la finalidad del informe no es la de asistir en la toma de decisiones judiciales, sino que, a su juicio, el informe serviría para basar una declaración de inimputabilidad de la persona condenada y proceder en consecuencia a la imposición de una medida de seguridad. De ahí que manifiesten que sólo lo solicitan 'si lo pide la parte', o que ello es un 'tema de la defensa', o que 'debía pedirse en la fase de instrucción', o 'debía pedirse en la fase intermedia'.

Una vez que el juez ha decidido suspender la pena de prisión e imponer el programa formativo, el juez no precisa cuánto tiempo durará el programa o de cuántas sesiones constará. Tampoco la ley específica la duración de los programas y el juez únicamente dicta que éste deberá llevarse a cabo durante los siguientes dos años, que generalmente es el plazo de suspensión de la pena. Por consiguiente, el número de horas

\footnotetext{
${ }^{13}$ Desembre 2008. Assessorament tècnic penal. Descriptors estadístics. Secretaria de Serveis Penitenciaris, Rehabilitació i Justícia Juvenil.
}

Revista Española de Investigación Criminológica

Artículo 1, Número 8 (2010) $\quad$ www.criminología.net

ISSN: 1696-9219 
y la duración de los cursos lo deciden las instituciones en las que se llevan a cabo los $\operatorname{programas}^{14}$.

La diversidad del contenido de la pena a que ello puede dar lugar puede observarse comparando las tres entrevistas individuales y 12 sesiones efectuadas en tres meses que acostumbran a durar estos programas en Catalunya, con los realizados en Valencia que consisten en tres entrevistas (motivacionales) previas, seguidos de 52 sesiones que se cumplen en 12 meses. ${ }^{15}$

Es curioso también observar que en las entrevistas realizadas para llevar a cabo este trabajo se pudo constatar que los jueces de ejecución creen que la duración de los programas la establece la Administración y ésta por su parte cree que la duración la determinan los jueces. En realidad parece más bien que la duración viene establecida por la oferta que las instituciones hacen a la Administración, oferta que en algunos casos viene condicionada por el presupuesto, pero no en todos, pues la entrega de muchas personas suple la falta de presupuesto.

Esta falta de determinación temporal del contenido de la pena, o de las obligaciones que deben ser cumplidas durante el período de suspensión de la condena de prisión, alcanza también a la prohibición de aproximación, ya que en tanto algunos jueces imponen el mismo plazo de la suspensión, otros establecen una duración autónoma de las distintas prohibiciones (José Antonio Rodríguez, comunicación personal).

Los dos temas que en esta fase de ejecución merecen a mi juicio una mayor investigación son:

a) La conveniencia de sugerir que el informe psicosocial sea obligatorio. Esta propuesta requeriría pensar qué cambios procesales son indispensables, especialmente en el marco de los juicios rápidos o en las sentencias de estricta conformidad. $^{16}$

\footnotetext{
${ }^{14}$ Evidentemente este no es el único supuesto en el que los técnicos de la Administración de Justicia proceden a determinar la duración precisa, o el contenido exacto de la pena. Para una visión magistral respecto de esta problemática véase JACOBS (1982).

15 María Victoria Lorenzo (Comunicación presentada en VI Congreso de Español de Criminología (Santiago de Compostela, 18, 19 y 20 de junio, 2009). Véase también LILA/CONCHELL (2009). Agradezco la ayuda de Javier Guardiola para la aclaración de este punto.

${ }^{16}$ Por otro lado, la ley integral prevé la existencia de unidades de valoración forense integral, vinculadas a los Jueces de Violencia sobre la Mujer, las cuales pueden también asistir en la decisión judicial. Habrá que analizar cuál es su funcionamiento y cómo se coordinan con los Equipos ya existentes de Asesoramiento Penal. En Catalunya se ha iniciado una prueba piloto el 15 de setiembre de 2009. Puede verse información en:
} 
b) La necesidad de determinar de forma más precisa la duración temporal de las reglas que se imponen en los casos de suspensión de la pena de prisión.

\subsection{El Delegado de Ejecución de Medidas, DEM ('agente de probation')}

El segundo actor que es necesario considerar son los Delegados de Ejecución de Medidas (DEM, una figura similar al 'agente de probation' en Inglaterra). En Barcelona los DEM están especializados, esto es, hay 17 delegados que se ocupan exclusivamente de la ejecución de programas formativos (y no de trabajo en beneficio a la comunidad).

$\mathrm{Su}$ papel es realizar una nueva entrevista con el acusado y elaborar un plan de trabajo individual, es decir un escrito en el que, basándose en la actitud del condenado sobre el delito cometido, la relación con la víctima y especialmente evaluando su actitud por lo que respecta a tomar parte del programa, se clasifica al acusado, con base en un instrumento de evaluación del riesgo, una versión adaptada y más corta del SARA, en una categoría de riesgo (alta, moderada o baja). En este Plan de Trabajo individual se recoge además la situación laboral de la persona, se concretan los plazos en que deberá cumplir el programa formativo, así como los compromisos que deberá respetar con la institución. Finalmente este escrito se remite al juez de ejecución (o al juez sentenciador en su caso).

Estos informes también se envían al coordinador de los DEM, quien en función de las plazas disponibles en los diferentes programas, el perfil y los horarios disponibles, asigna al condenado a una de las instituciones que llevan a cabo los programas. Una vez realizada la asignación, el DEM se pone en contacto con el condenado y le pide que se comunique con la institución para empezar el programa formativo ${ }^{17}$.

En esta fase de ejecución emergen dos problemas a mi parecer. Por un lado, el trabajo de los DEM es realizar unas entrevistas iniciales con base en las cuales elaborar el Plan de Trabajo Individual, pero también deben realizar un seguimiento del cumplimiento de los programas formativos. Esta tarea de seguimiento puede verse quizás dificultada por el hecho de que si bien los DEM están especializados en programas formativos, no se dedican exclusivamente a tratar con personas condenadas

http://www20.gencat.cat/portal/site/Adjucat/menuitem.5241ca2acc8cf176b1893110b0c0e1a0/?vgnextoid $=$ efb0132be0372210VgnVCM1000008d0c1e0aRCRD\&vgnextchannel=efb0132be0372210VgnVCM100 0008d0c1e0aRCRD\&vgnextfmt $=$ default

${ }^{17}$ En el caso en que el condenado haya sido clasificado como de 'alto riesgo' la institución se pone en contacto con él directamente.

Revista Española de Investigación Criminológica

Artículo 1, Número 8 (2010) $\quad$ www.criminología.net

ISSN: $1696-9219$ 
por violencia de género, sino que también tratan, y cada vez en mayor medida, con personas condenadas por delitos contra la seguridad vial.

Un segundo aspecto relacionado con el trabajo de los DEM es sin duda la creciente carga de trabajo que soportan. Así por ejemplo, según las diversas fuentes entrevistadas, se estima que cada DEM tiene a cargo entre 50 y 80 personas condenadas. Ello comporta no sólo una carga difícilmente asumible para el delegado, sino que también conlleva probablemente que su propia función se vea desdibujada, al pasar de prestar una atención individualizada a constituirse en un 'gestor de riesgos ${ }^{18}$.

Finalmente no hay que olvidar la lista de espera existente, que se ha incrementado del 33\% en el año 2008 al 60\% (ESTADÍSTICA BÀSICA, 2009). Ello no implica que estas penas prescriban, como acostumbra a creerse, pero sí es probablemente cierto que estas listas de espera contribuyan a disminuir la confianza de los jueces en estas penas alternativas a la prisión, pues estos tienden a creer que no se cumplen precisamente porque prescriben (BLAY, 2007).

El segundo problema que existe en este momento de la ejecución se refiere a las personas que el Departamento de Justicia considera no aptos para poder seguir el programa formativo. Esta situación surge cuando se dan algunos factores como el alcoholismo y otros problemas de drogadicción, el desconocimiento de la lengua, o que la persona condenada sea una mujer por un delito de violencia doméstica (ya que los programas están diseñados exclusivamente para hombres).

En concreto, en los casos de personas que presentan problemas de alcoholismo o drogadicción, y dado que imponer una pena de prisión se considera inapropiado en estas circunstancias, el DEM intenta movilizar el resto de servicios sociales generales. Ahora bien debe recordarse que la persona no ha sido condenada a seguir un programa de deshabituación ni un programa de tratamiento por drogas. Por ello algunos jueces cuando son conscientes de que existe esta situación aplican la suspensión de la pena especial para drogodependientes (art.87), en tanto que otros manifiestan que esta suspensión no puede aplicarse sin que en la sentencia se declare probada la drogadicción. ${ }^{19}$

\footnotetext{
${ }^{18}$ Esta idea proviene de BLAY (2010) referida a los cambios que conlleva la masificación de la pena de trabajo en beneficio a la comunidad. Puede leerse también en MORGAN (2003).

${ }^{19}$ Con la consecuencia eventual de que en este supuesto procedería declarar una atenuante o una declaración de semiimputabilidad o inimputabilidad. La apreciación de una atenuante no tendría excesivos efectos prácticos puesto que los jueces ya aplican la pena mínima (María Dolors Leyva, comunicación personal).
}

Revista Española de Investigación Criminológica

Artículo 1, Número 8 (2010) $\quad$ www.criminología.net

ISSN: $1696-9219$ 
Este problema de personas a las que se considera incapaces de realizar un programa formativo hasta que no confronten sus problemas de alcoholismo acostumbra a ser orillado en la actualidad, en ocasiones, con la imposición de una regla de conducta adicional en la suspensión de la pena ordinaria, dirigida a conseguir que la persona realice un tratamiento de deshabituación y posteriormente acuda al programa formativo específico de violencia de género.

En cualquier caso creo que esta problemática refleja el inconveniente de una regulación legal que obliga a imponer siempre que se suspende la pena de prisión, un programa formativo. Y manifiesta también el proceder desacertado de imponer un programa formativo sin informe criminológico que confirme que éste puede ser cumplido por esta persona concreta.

\subsection{Las instituciones privadas}

Una vez el condenado es derivado al programa formativo, el tercer actor que interviene en la ejecución actualmente en Barcelona se encuentra constituido por cuatro organizaciones privadas (entidades colaboradoras de la Administración y subvencionadas por ésta). Esta privatización pasa a menudo inadvertida en los debates sobre el sistema penal, y posiblemente produzca determinados efectos que en estos momentos sólo podemos intuir.

Dado que la medida obligatoria de realizar un programa formativo entró en vigor en junio de 2005, el Departamento de Justicia de Cataluña se vio obligado a aceptar las instituciones existentes para ejecutar los programas sin proceso de acreditación que permitiese garantizar la aptitud y homogeneidad de las mismas (GELDSCHLÄGER, 2009).

Además, el hecho de que el Departamento de Justicia reciba numerosos condenados conlleva una inmensa presión para las instituciones, lo cual repercute en un aumento del número de personas en cada grupo de condenados, en la reducción de las sesiones o del personal cualificado. Estas instituciones se enfrentan pues a problemas como una alta movilidad del personal, su falta de estabilidad o su limitada formación.

Una de las propuestas para hacer frente a estos costes es imponer la carga al condenado de que contribuya al coste del programa, como parece ser que sucede ya en el $54 \%$ de los programas europeos (GELDSCHLÄGER, 2009). 
Un problema adicional importante es la tasa de abandono, esto es, las personas que una vez asignadas a una institución no acuden a la primera sesión o acuden de forma esporádica. Sabemos, por las investigaciones de otros países, que uno de los grandes problemas de los Programas Formativos, es la dificultad de conseguir que las personas condenadas asistan a todas las sesiones. Así, estudios internacionales ponen de manifiesto que la tasa de abandono están entre el 23\% y el 29\% (SCOTT, 2004).

El Departamento de Justicia no dispone o no facilita los datos sobre la tasa de abandono. Es cierto que debería precisarse la definición de 'abandono', puesto que una persona condenada puede no asistir al programa concreto al cual ha sido asignado y no obstante acabar cumpliendo la obligación en otro programa en el transcurso de los dos años de suspensión de la pena. O también puede no asistir en dos ocasiones de forma justificada y ello no computa como 'abandono' (Juanjo Subero, comunicación personal). A mi juicio no obstante y dado que los abandonos indican un mayor riesgo de reincidencia (SCOTT, 2004), sería importante conocer y prestar atención a este dato.

La reacción frente al abandono también merece ser debatida. De acuerdo al tenor literal de la ley, una vez que la obligación de realizar programas formativos es impuesta por el juez, si el agresor abandona los cursos, el juez debe proceder a la revocación inmediata de la suspensión de la pena de prisión. Esta regulación legal es más restrictiva que en otros casos de suspensión de la pena, en los que el juez tiene más flexibilidad para reaccionar en casos de incumplimiento y no revocar la suspensión de la condena (art. 84.3 CP).

Aunque no se ha llevado a cabo ninguna investigación específica por ahora sólo nos consta de un caso $^{20}$ de revocación basado en la no asistencia a los programas formativos, y la sensación generalizada es que si un agresor no va al programa, los mecanismos para compelerle no son muy efectivos.

El proceso que en la práctica se sigue en Catalunya es que si el condenado incurre en dos faltas de ausencia injustificadas el delegado informa al juez.

Este proceder es similar al expuesto por CID (2009:136-138) en los casos de suspensión especial por motivos de drogodependencia, en los que si bien los términos

\footnotetext{
${ }^{20}$ Aparentemente la única sentencia es la AAP Madrid, 116/2007, de 19 de Febrero; JUR 2007/175098). Datos facilitados por José Cid (aunque su investigación se centra únicamente en los casos en los que en un recurso se deniega la revocación, encontrar solo uno es indicativo de que debe haber pocas revocaciones de la suspensión de la pena en este ámbito, pues es plausible pensar que estas revocaciones, si existiesen, serían recurridas).
}

Revista Española de Investigación Criminológica

Artículo 1, Número 8 (2010) $\quad$ www.criminología.net

ISSN: $1696-9219$ 
de la ley (art.87.5) estipulan que la suspensión se revoca por el abandono del tratamiento, diversas sentencias interpretan que el incumplimiento sólo se produce cuando hay un 'rechazo injustificado' a realizar dichos programas. En opinión de CID (2009:138), con quien concuerdo, la revocación de la suspensión sólo procedería cuando, sobre la base de un informe criminológico, pudiera concluirse que existe un riesgo de reincidencia.

No obstante, como defenderé en las conclusiones, además de la revocación deberían preverse 'sanciones intermedias', pues en los delitos de violencia de género lo que quizás sucede es una falta de reacción judicial incluso en los casos de 'rechazo injustificado'. Pues aun cuando se producen dos faltas de asistencia injustificada algunos jueces sólo amonestan a la persona, pero no revocan la suspensión de la pena, ni pueden adoptar legalmente otra medida adicional.

Una dificultad ulterior es determinar los criterios con base en los cuales se decide que el programa ha sido cumplido de forma exitosa. Recordemos que en función del informe que escriban estas instituciones, el juez declara cumplida la obligación impuesta en la suspensión de la condena de prisión y procede a acordar la remisión de la pena.

Los participantes pueden asistir, o 'calentar la silla' como se afirma coloquialmente, y no participar activamente en el programa. Además, teniendo en cuenta la lista de espera existente, hay una presión implícita para 'aprobar' a todos los participantes. Y tampoco debe olvidarse que 'suspender' el programa conllevaría, según la ley, la entrada en prisión.

A mi juicio sería deseable una mayor reflexión sobre cuándo se considera cumplido el Programa Formativo. Si el criterio de éxito exclusivo es 'acudir a las sesiones', entonces uno debería reconsiderar esta pena en términos de 'privación de tiempo', que no es poco, e intentar concebir una cantidad proporcional de tiempo que el condenado debe cumplir como pena.

Es cierto que ello puede conllevar que esta pena pierda su significado original, pero también debe advertirse que alguno de los objetivos que en ocasiones se plantean, como abordar el significado qué tiene la violencia, o ayudarles a entender 'la continuidad entre la masculinidad del hombre como agresor y la masculinidad de los hombres que no son violentos' (GADD 2004:188; HEARN/WHITEHEAD, 2006:48), parecen extremadamente ambiciosos y difíciles de lograr en tres meses.

Revista Española de Investigación Criminológica

Artículo 1, Número 8 (2010) $\quad$ www.criminología.net

ISSN: $1696-9219$ 
Un último problema detectado es la falta de atención a la seguridad de las mujeres cuyas parejas masculinas han sido condenadas a realizar un programa formativo.

El sistema penal español prohíbe el contacto entre el condenado y la mujer, aunque diversas investigaciones comparadas muestran que en la práctica muchas mujeres continúan con la relación (ROBINSON/COOK, 2006; HOYLE, 2007). Y debido a que se parte de que hay una prohibición de aproximación en vigor, no se presta suficiente atención a la seguridad de las mujeres mientras el agresor está cumpliendo la medida de asistir a un programa formativo.

El problema se complica puesto que si bien la pareja denunciante quizás es conocida y está en contacto con la Administración, a través de la Oficina de Atención a la Víctima por ejemplo, en el supuesto de que la persona condenada tenga una nueva pareja, esta no es conocida por la Administración y no hay ningún mecanismo previsto a través del cual pueda ser alertada de que su pareja actual está cumpliendo una pena por violencia de género (Heinrich Geldschläger, UPF, 3 de julio de 2008).

Además surgen problemas relativos a si el hombre agresor condenado tiene derecho a que su pareja actual no sepa que está asistiendo a un programa formativo. Evidentemente hay que ponderar el derecho a la resocialización y a la intimidad con el derecho a la integridad de la mujer.

Expuesta la ejecución quedaría pendiente la evaluación de los programas formativos. Es cierto que estos programas han proliferado en Europa, pero ello parece obedecer más a la necesidad de reconciliar diversas demandas concurrentes (una petición de castigos más severos, una presión de grupos feministas y una defensa de los programas cognitivo-conductuales), que a la evidencia del éxito de dichos programas (GADD, 2004).

La evaluación de los programas formativos es pertinente, para intentar entender no solo qué funciona sino también por qué lo hace (LEWIS, 2004: 207-218). Y es importante asimismo para intentar comprobar la efectividad del sistema penal respecto de otros medios fuera del sistema de justicia penal (ROBINSON/COOK, 2006:194) ${ }^{21}$.

\footnotetext{
${ }^{21}$ En este sentido es necesario repetir que la prohibición de mediación impuesta por la Ley Integral parece totalmente apresurada (LARRAURI, 2007). También se debe destacar la falta de programas comunitarios voluntarios, que en ocasiones no existen ni para las personas que manifiestan su interés en continuar algún tipo de tratamiento después de haber cumplido la condena (Geldschläger, UPF, 3 de julio de 2008).
}

Revista Española de Investigación Criminológica 
En España hay que destacar dos experiencias evaluadoras. Una realizada por el Departamento de Justicia de Cataluña, que ha iniciado una investigación para conocer la tasa de reincidencia (y que concluirá en el próximo año 2010). Esta experiencia es en mi opinión parcialmente positiva porque estos programas debieran ser no sólo evaluados por sus tasas de reincidencia, sino también con entrevistas a mujeres, las cuales nos permitirán detectar previsiblemente un mayor índice de victimización y nos posibilitaría además conocer su opinión (por ejemplo acerca de cómo esta medida incrementa su seguridad).

La otra experiencia evaluadora es la realizada por el Observatorio Estatal de Violencia sobre la mujer -Ministerio de Igualdad- que publicó su Informe de la Evaluación de la Aplicación de la Ley Integral el 24 de julio de 2008. En este se afirma ya en el inicio (página 2) que 'Más de 53.000 hombres han sido condenados a penas de prisión por violencia de género en estos años'.

Debe señalarse que este dato es extremadamente ambiguo. Las 53.282 penas de prisión no suponen 'entrada' en prisión, no son datos de penas definitivas ejecutadas, sino datos de condenas a prisión respecto de las cuales puede adoptarse la decisión de suspender su ejecución. No sabemos, porque el Informe nada indica acerca de ello, cuántas de estas penas de prisión se suspenden y en cuantas se impone un programa formativo.

Es desolador que no haya ninguna mención respecto de la pena de Trabajo en Beneficio a la Comunidad o los Programas Formativos, perpetuando así la idea de que la única pena es la prisión. El único dato del que disponemos para el resto de España es el presentado por ARCHANCO (2009) quien informa acerca de 14.925 personas cumpliendo un Programa Formativo, sin más aclaraciones. Esta cifra, no precisamente pequeña, debería justificar una mayor atención a este tipo de programas.

Además esta falta de atención a los programas formativos es, a mi juicio, censurable por los siguientes motivos. Por un lado, debe recordarse que una de las novedades de la Ley Integral fue precisamente la obligación dirigida a los jueces de que impusieran siempre un programa formativo. Hubiera sido esperable un mayor interés en evaluar el impacto de esta medida. Por otro lado, debe enfatizarse que numerosas investigaciones (ROBINSON/COOK, 2006:194) advierten que uno de los motivos más citados por la víctima para explicar su retirada del sistema penal, es que ella quiere 'rehabilitarle' y no castigarle. Por lo que una mayor atención a los programas

Revista Española de Investigación Criminológica 
formativos redundaría no sólo quizás en mejores perspectivas de rehabilitación, sino también en más confianza de las víctimas en el sistema penal, lo que incidiría positivamente en la disminución de la tasa de retirada de denuncias, negativas a declarar o retractaciones.

\section{3.- CONCLUSIONES EN TORNO A LAS PENAS DE LA VIOLENCIA DE GÉNERO OCASIONAL}

Expuesta brevemente la investigación sobre los programas formativos quisiera finalizar con una serie de reflexiones dirigidas a intentar mejorar los diversos problemas de ejecución que la actual regulación de los programas formativos en el sistema de penas del código penal español conlleva.

1) Una primera consideración es que, a mi juicio, los programas formativos no debieran ser la respuesta penal utilizada para los casos más leves de violencia de género ocasional. Debe reiterarse de nuevo la necesidad de diferenciar distintos tipos de violencia de género en función de su gravedad (LARRAURI, 2007; JOHNSON, 2008). En mi opinión además no se calibra bien ni la carga punitiva, ni la laboriosa ejecución que, como puede verse en el cuadro al final del texto, estas medidas comportan. Por ello, para los casos más leves procede discutir la (re) introducción de la multa u otras penas de análoga severidad (MAIR, 2004) como por ejemplo la amonestación.

2) Una segunda sugerencia es que la obligación de asistir a los programas formativos no debiera ser una medida obligatoria en todos los supuestos de suspensión o sustitución de la pena de prisión. Esta regulación no permite a los jueces ejercer la discrecionalidad de decidir quién debería ser enviado a un programa formativo por tener mayor necesidad o riesgo; y quien no debiera ser enviado porque no es necesario o porque no puede cumplirlo. En consecuencia, mi recomendación sería que la imposición de esta regla de conducta fuera una facultad discrecional de los jueces.

Soy consciente de que cualquier propuesta tendente a individualizar la condena en función del riesgo o necesidades criminógenas entrará en tensión con el principio de proporcionalidad, que obliga a que el juez concrete la pena en función de la gravedad del hecho. Y debido a que en un sistema más individualizado no todos los condenados

Revista Española de Investigación Criminológica

Artículo 1, Número 8 (2010) $\quad$ www.criminología.net

ISSN: 1696-9219 
recibirían esta pena adicional, se podría concluir que añadir un programa formativo representaría una 'amenaza a la proporcionalidad' (HOYLE, 2007; NETTER, 2007).

Entiendo que si se acepta esta propuesta interpretativa la tensión es hasta cierto punto inevitable, si se pretende que la pena se imponga no sólo con base en la gravedad del hecho, sino también en función del riesgo o "necesidades criminógenas' ${ }^{22}$ de la persona condenada (HANNA-MOFFAT, 2005; RAYNOR, 2007).

Esta mayor discrecionalidad debería ir acompañada de una regulación más precisa de los casos en los que se estima indispensable un informe criminológico para adoptar diversas decisiones, el cual de forma similar al Pre-Sentence Report (TATA/BURNS/HALLIDAY/HUTTON/MCNEILL, 2008), permitiera al juez conocer las circunstancias sociales, personales y demás variables relevantes para la decisión acerca de la imposición o no de un Programa Formativo.

El informe criminológico plantea además otras cuestiones extremadamente interesantes como la necesidad de estudiar qué impacto tiene este informe en las sentencias; en qué tipo de delitos se debería solicitar inexcusablemente; o la entrada del poder de los técnicos (psico-sociales o criminólogos) en la administración de justicia (BOONE, 2009).

3) Una tercera reflexión es acerca de la conveniencia de que esta medida pueda imponerse directamente, sin necesidad de vincularla a una pena de prisión que debe ser suspendida. Ello evitaría que resurja la pena de prisión en casos de revocación de la suspensión (pues la reacción al quebrantamiento de condena sería una pena de multa). Y el problema de que la persona debe consentir, y que por ello no puede ser una pena principal, puede obviarse imponiendo los programas formativos como pena principal opcional.

Creo que con esta propuesta se conseguiría también reducir la retractación de las mujeres víctimas de violencia de género. Sin duda el tema de la retirada de denuncias, negativas a declarar y retractaciones obedece a numerosos motivos. Pero un tema recurrente es el hecho que la mujer no quiere que su marido vaya a prisión o no quiere que vaya a prisión 'por culpa suya'.

\footnotetext{
${ }^{22} \mathrm{El}$ hecho de que se atienda más a necesidades sociales que al riesgo de reincidencia, puede entenderse como un intento de acercar el modelo del riesgo a un modelo de justicia; además en opinión de Raynor/Robinson (2009) los actuales modelos rehabilitadores están más basados en el aprendizaje que en el tratamiento por lo que asumen una imagen del actor como un 'agente moral'.
}

Revista Española de Investigación Criminológica

Artículo 1, Número 8 (2010) $\quad$ www.criminología.net

ISSN: 1696-9219 
El hecho de que se posibilite, y sea conocido por la mujer, que el hombre reciba como condena la asistencia obligatoria a un programa formativo puede favorecer el hecho de que la mujer persista en la denuncia al estar más acorde lo que ella quiere con lo que el sistema penal impone.

4) También sería deseable permitir la imposición del programa formativo con el Trabajo en Beneficio a la Comunidad, a modo de pena combinada. En este sentido la regulación actual es deficitaria, pues no prevé la posibilidad de que el juez cuando condena a trabajo en beneficio a la comunidad como pena principal imponga además la obligación de participar en un programa formativo. Por otro lado, quizás la posibilidad de imponer una pena combinada ayudaría a combatir la convicción existente entre los jueces de que si tiene antecedentes ya debe imponerse la pena de prisión, aun cuando pueden legalmente imponer Trabajo en Beneficio a la Comunidad.

5) Creo que sería también necesario debatir la posibilidad de que el legislador determine de forma más precisa la duración temporal de esta medida, para evitar disparidades como las señaladas en Valencia (12 meses/52 sesiones) o en Barcelona (3 meses/12 sesiones). Y reflexionar además acerca de si esta duración debiera admitir cierta variación en función del distinto perfil de riesgo de las personas condenadas (Juanjo Subero, comunicación personal). Ello permitiría que esta pena no fuera destinada sólo a los casos más leves sino que pudiera ser adecuada para personas que representan un riesgo mayor.

6) Por último, es preciso repensar la reacción penal frente al abandono injustificado. GONDOLF (2002) ha argumentado de forma convincente que para que un programa 'funcione', tiene que estar integrado en un 'sistema de intervención', en el sentido de que haya una reacción policial o judicial inmediata en el caso de que el agresor no asista al programa formativo.

En Cataluña, los psicólogos que realizan el programa y los delegados de ejecución de medidas que se encargan de controlar el cumplimiento por parte del condenado remiten el expediente al juez, como ya he expuesto, cuando se producen dos faltas injustificadas. Y se quejan en ocasiones de la falta de respuesta judicial en estos 
supuestos. Por su parte, los jueces no se sienten excesivamente cómodos ante la decisión de encarcelar a estos delincuentes primarios.

Quizás elaborar unas guías penológicas más precisas de cuándo debe considerarse esta medida infringida, y dar además a los jueces la posibilidad de reaccionar ante algunas infracciones de otra forma que no fuera la ejecución de la pena de prisión (VON HIRSCH, 1993), les permitiría dar respuestas más proporcionales a las infracciones. Sería ésta una alternativa que no desembocaría en un sistema draconiano, que amenaza con la prisión a quien incumple una regla de conducta impuesta en la suspensión de la pena; inseguro, porque la revocación depende de cuántas advertencias está dispuesto a hacer el delegado o el juez; y quizás en últimas inefectivo, pues acaba no reaccionando frente a los incumplimientos. 


\section{LOS PROGRAMAS}

FORMATIVOS

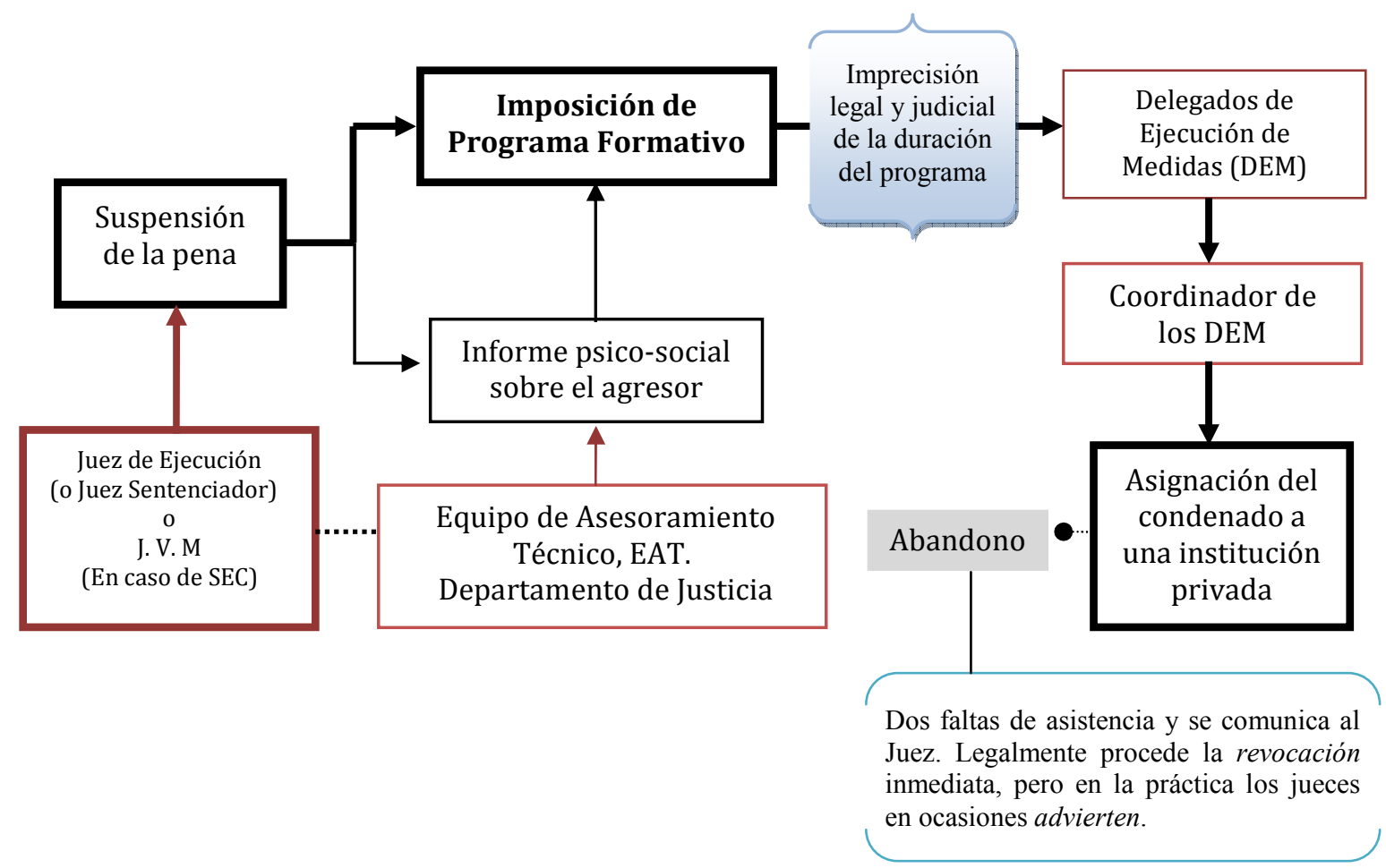

Cuadro elaborado por el profesor William Freddy Pérez, a quien agradezco su esfuerzo en entender y hacer comprensible el proceso de ejecución de los Programas Formativos.

Revista Española de Investigación Criminológica

Artículo 1, Número 8 (2010) $\quad$ www.criminología.net

ISSN: $1696-9219$ 


\section{BIBLIOGRAFÍA}

ANTÓN, L. / LARRAURI, E. (2009) Violencia de género ocasional: un análisis de las penas ejecutadas $R E I C$, http://www.criminologia.net/reic.html

ARCHANCO, C. (2009) Penas y Medidas Alternativas a la Prisión. Violencia de género. Ponencia presentada en el III Congreso del Observatorio contra la Violencia doméstica y de género. Madrid, 22 de octubre, 2009.

BLAY, E. (2007) El trabajo en beneficio de la comunidad como pena para la violencia familiar, Revista de Derecho Penal y Criminología, 19:379-426.

- (2010) 'It could be us': Recent transformations in the use of community service as a punishment in Spain. European Journal of probation (en prensa).

BOONE,M. (2009) Meting out Punishment with a view to Influencing Behavior: The Court versus the probation. Ponencia presentada en el IX Congreso Europeo de Criminología (ESC), Ljubiana.

BOTTOMS, A.E. / REX, S. / ROBINSON,G. (2004) How did we get here?, Bottoms, A.E./Rex, S. and Robinson,G. (eds) Alternatives to Prison: Options for an insecure society. Cullompton, Willan.

BUENO ARÚS,F. (1985) A propósito de la reinserción social del delincuente, Cuadernos de Política Criminal, $\mathrm{n}^{\circ} 25$.

CID,J. (2009) La elección del castigo. Barcelona, Bosch.

CID, J. / LARRAURI, E. (2002) Jueces Penales y Penas en España. Valencia, Tirant lo Blanch.

- (2005) Penas Alternativas y Delincuencia Violenta, en CID, J.- LARRAURI, E. (coords) Delincuencia violenta: Castigar o prevenir. Valencia, Tirant lo Blanch

ECHEBURÚA, E. / FERNÁNDEZ-MONTALVO, J. (2007) Male Batterers with and without Psychopathy: An Exploratory Study in Spanish Prisons, International Journal of Offender Therapy and comparative criminology, 51 (3)1254-1263.

ESTADÍSTICA BÀSICA (2009) Serveis Penitenciaris, Rehabilitació i Justicia Juvenil. Generalitat de Catalunya, Departament de Justicia.

http://www20.gencat.cat/portal/site/Justicia/menuitem.cc15117

FERNÁNDEZ-MONTALVO, J. / ECHEBURÚA, E. / AMOR, P. (2005) Aggressors against women in prison and in the community: an exploratory study of a differential profile, International Journal of Offender Therapy and comparative criminology, 49 (2)158-167.

GADD, D. (2004) Evidence-Led Policy or Policy-Led Evidence?: Cognitive Behavioural Programmes for Men who are Violent towards women, Criminal Justice 4 (2):173-197.

GELDSCHLÄGER,H. (2009) Programas de rehabilitación como Medida penal Alternativa para hombre condenados por violencia doméstica/de género. Ponencia presentada en el III Congreso del Observatorio contra la Violencia doméstica y de género. Madrid, 22 de octubre, 2009.

GONDOLF, E. (2002) Batterer Intervention Systems. London, Sage.

HANNAH-MOFFAT,K. (2005) Criminogenic needs and the transformative risk subject: Hybridizations of risk/need in penality. Punishment \& Society, 7/1:2953.

HEARN, J. / WHITEHEAD, A. (2006) Collateral damage: Men's 'domestic' violence to women seen through men's relations with men, Probation Journal, 53 (1): $38-56$.

Revista Española de Investigación Criminológica

Artículo 1, Número 8 (2010) $\quad$ www.criminología.net

ISSN: $1696-9219$ 
HOYLE, C. (2008) Will she be safe? A critical analysis of risk assessment in domestic violence cases, Children and Youth Services Review. Vol. 30/3: 323-337.

JACOBS, J. (1982). Sentencing by Prison Personnel: Good Time. UCLA Law Review $30,217-270$

JOHNSON, M (2008) A typology of Domestic Violence. Intimate Terrorism, Violent Resistance and Situational Couple Violence. Lebanon, Northeastern University Press.

LARRAURI, E. (2004) ¿Es posible el tratamiento de los agresores de violencia doméstica? En López Barja de Quiroga, J./Zugaldia Espinar,J.M. (coords) Dogmática y Ley Penal. Libro Homenaje a Enrique Bacigalupo. Madrid, Marcial Pons.

- (2007) Criminología Crítica y Violencia de Género. Madrid, Trotta.

- (2009a) Igualdad y violencia de género: Comentario a la STC 59/2008. Indret http://www.indret.com

- (2009b) Desigualdades sonoras, silenciosas y olvidadas: género y derecho penal, en Alfonso Ruiz Miguel/Andrea macía Morillo (eds) Desafíos de la igualdad, desafíos a la igualdad. Anuario de la Facultad de Derecho de la UAM: Madrid.

- (2010) Actitudes judiciales y violencia de género. Investigación en curso.

LEWIS, R. (2004) Making Justice Work. Effective Legal Interventions for Domestic Violence, British Journal of Criminology, 44/2:204-224.

LILA,M./CONCHELL,R. (2009) Programa Contexto: programa de intervención para maltratadores en la provincia de Valencia, en ReCrim, http://www.uv.es/recrim

MAIR, G. (2004) Diversionary and non-supervisory approaches to dealing with offenders, in BOTTOMS,A./REX,S/ROBINSON,G. (eds) Alternatives to Prison. Cullompton, Willan.

MARTINEZ,M./PEREZ,M. (2009) Evaluación de un programa de tratamiento con maltratadores encarcelados. Boletín Criminológico, Julio-Agosto, $\mathrm{n}^{\circ} .115$.

MINISTERIO DE IGUALDAD (2008) Evaluación de la aplicación de la Ley Orgánica 1/2004 de 28 de diciembre. Informe Ejecutivo. http://www.migualdad.es/

MORGAN,R.(2003) Thinking about the demand for probation services. Probation Journal 50 (1):7-19

MUÑOZ CONDE, F. (1979) La resocialización del delincuente: Análisis y Crítica de un Mito, Sistema, 31. Pags. 73-84.

NETTER, B. (2007) Using Group Statistics to Sentence Individual Criminals: an Ethical and Statistical critique of the Virginia Risk Assessment Program, The Journal of Criminal Law \& Criminology, 97/3: 699-729.

RAYNOR,P. (2007) Risk and need assessment in British probation: the contribution of LSI-R, Psychology, Crime \& Law, 13 (2):125-138.

REDONDO, S. / POZUELO, F. / RUIZ, A. (2007) El tratamiento en las prisiones: Investigación Internacional y su situación en España, Cerezo, A. / García, E. (coords) La prisión en España. Granada, Comares.

ROBINSON, A./COOK, D. (2006) Understanding Victim Retraction in Cases of Domestic Violence: Specialist Courts, Government Policy, and Victim-Centred Justice, Contemporary Justice Review, vol.9, $\mathrm{n}^{\circ}$ 2, 189-213.

ROBINSON, G. / MCNEILL, F. (2004) Purposes matter: examining the 'ends' of probation, Mair, G.(ed) What matters in Probation. Cullompton, Willan.

RUEDA,M.A. (2007) Los programas y/o tratamientos de los agresores en supuestos de violencia de género. Madrid,Dykinson.

Revista Española de Investigación Criminológica

Artículo 1, Número 8 (2010) $\quad$ www.criminología.net

ISSN: $1696-9219$ 
SCOTT, K. (2004) Predictor of Change among Male Batterers, Trauma, Violence \& Abuse, vol. 5, $\mathrm{n}^{\mathrm{0}} .3,260-284$

TATA, C. / BURNS, N. / HALlidAY, S./ HUTTON, N. / McNEILL, F. (2008): Assisting and advising the sentencing decision process. British Journal of Criminology, 2008, 48: 835-855.

VON HIRSCH, A. (1993) Censure and Sanctions. Oxford, Oxford University Press. Traducción al castellano, Censurar y Castigar, Madrid, Trotta, 1998.

Elena Larrauri es catedrática de derecho penal y criminología en la Universitat Pompeu Fabra. Su última publicación es Criminología Crítica y Violencia de Género (2007) Madrid, Trotta. 